\title{
Evaluación clínica de hernioplastia umbilical en bovinos: empleo de fascia abdominal autógena
}

\section{Clinical evaluation of umbilical hernia surgery in calves: use of autogenous abdominal fascia}

\author{
Mastoby Martinez M, ${ }^{*}$ M.Sc, Carlos Oviedo $\mathrm{P},{ }^{1} \mathrm{MVZ}$, J uan Ballut $\mathrm{P},{ }^{1} \mathrm{M} . \mathrm{Sc}$. \\ ${ }^{1}$ Universidad de Córdoba, Facultad de Medicina Veterinaria y Zootecnia, Departamento \\ de Ciencias Pecuarias, Montería, Colombia *Correspondencia: mastobymvz@hotmail.com \\ Recibido: Septiembre 18 de 2009; Aceptado: Marzo 23 de 2010.
}

\section{RESUMEN}

Objetivo. Evaluar clínicamente la hernioplastia umbilical en terneros con el empleo de fascia abdominal autógena. Material y métodos. Fueron utilizados cinco terneros de raza Brahman (6-12 meses) y peso promedio de $200 \mathrm{~kg}$, los terneros se intervinieron quirúrgicamente por presentar hernia umbilical recidivante. El anillo herniario se reforzó con autoinjerto de fascia abdominal fijado con puntos en " $U$ " horizontales, con sutura de poliamida (50 libras de presión). El tejido conectivo subcutáneo se suturó con polyglactin 910 del calibre 2-0 en patrón de puntos continuos. En el posoperatorio, se evaluó la evolución clínica de la cicatrización cutánea y la presencia o no de recidiva herniaria por un periodo de 60 días. Resultados. En todos los animales se observó edema intenso de los focos quirúrgicos (foco donador en la región inguinal y foco receptor en la región umbilical), sin dehiscencia de la herida cutánea, abscedación, ni recidiva de la hernia. Conclusiones. La técnica quirúrgica utilizada y el autoinjerto de fascia abdominal fueron eficientes en la corrección de hernia umbilical recidivante en terneros, hecho que permite recomendarla en casos semejantes.

Palabras clave: Hernia, recidivante, ternero.

\section{ABSTRACT}

Objective. To evaluate from a clinical point of view the umbilical hernia surgery in calves by using autogenous abdominal fascia. Material and methods. Five Brahman calves were used (6-12 months) average weight of $200 \mathrm{~kg}$, calves were treated surgically by presenting recurrent umbilical hernia. Hernial ring was reinforced with abdominal fascia autograft fixed points U horizontal suture polyamide (50 pounds pressure). Subcutaneous connective tissue was sutured with polyglactin 910 2-0 gauge continuous dot pattern. After surgery, it was evaluated the clinical course of skin wound healing and the presence or absence of hernia recurrence for a period of 60 days. Results. All animals showed severe edema of the surgical 
focus (focus donor in the groin and the focus receiver in the umbilical region) without cutaneous wound dehiscence, abscess formation or hernia recurrence. Conclusions. The surgical technique used and the abdominal fascia autografts were efficient in the correction of recurrent umbilical hernia in calves, the successful procedure allows recommending in such cases.

Key words: Hernia, recurrent, calf.

\section{NTRODUCCI ÓN}

En la práctica de cirugía profesional en grandes animales es común el hallazgo de las hernias umbilicales. Estas se consideran como la salida de órganos de la cavidad abdominal a través del anillo umbilical y que se encuentran envueltos por el peritoneo parietal (1). El diagnóstico es básicamente clínico, encontrándose a la palpación los signos cardinales de esta patología como son: anillo, continente y contenido herniario, que se reduce con la presión manual (2). Aunque se trata de una patología de fácil diagnóstico, se puede utilizar la radiología y ultrasonografía para su confirmación (3). El éxito del tratamiento quirúrgico depende del diámetro del anillo, de la cantidad de contenido, de la resistencia de los tejidos localizados en los bordes del anillo, inflamación local, edad, peso del animal, manejo alimenticio y cuidados postoperatorios (4).

La hernia umbilical es una patología quirúrgica con alta recidiva, debido al mal posoperatorio (infecciones, dieta, reposo, etc.) y a la falta de opciones en aquellos animales de anillos herniarios de gran tamaño que son intervenidos con la técnica tradicional

Para estos casos de hernias grandes y complicadas, la variante está en el tipo de punto utilizado para cerrar el anillo pos reintroducción del contenido. Entre los tipos de puntos está, el simple, el Lembert (método de Roder), transversales (método de Bouchaert) (5). Otra forma puede ser la imbricación, que consiste en cerrar el anillo por medio de la superposición de los márgenes de los músculos rectos abdominales y fijación por medio de puntos en "u". Para las hernias pequeñas y no complicadas, se puede intentar la corrección con la suturación percutánea del anillo interno.

Dentro de uso de otras técnicas para tratar las hernias umbilicales están la aplicación de injertos, que se ajuste a una reconstrucción ideal, la cual debería proporcionar fascia vascularizada autógena y piel (colgajos miocutáneos), preferiblemente como una unidad y en un solo tiempo quirúrgico. Otras fuentes podrían ser el músculo tensor de la fascia lata y los propios tejidos del saco herniario.

Los implantes sintéticos y de naturaleza orgánica han sido utilizados en la reconstrucción de defectos tisulares abdominales, tanto en animales domésticos como en humanos (6). En el tratamiento de hernias umbilicales y de defectos de pared abdominal, se han utilizado con éxito diversos materiales como duramadre, cartílago auricular bovino conservado en glicerina al $98 \%(2,7)$ o en solución de glutaraldeido al $4 \%$ (8), mallas de metal, mallas de poliamida mono y polifilamentosa entre otras (6).

De acuerdo a lo anterior, es indispensable contar con una alternativa quirúrgica que sirva además de tratar hernias complicadas de anillos de gran tamaño por primera intención, como para corregir hernias umbilicales recidivantes intervenidas por el método tradicional. El objetivo del presente trabajo fue evaluar clínicamente la hernioplastia umbilical en bovinos con el empleo de fascia abdominal autógena. 


\section{MATERI AL Y MÉTODOS}

Sitio y tipo de estudio. La presente investigación fue de tipo experimental descriptivo. Se realizó en la Finca "La Esperanza" ubicada en el Departamento de Córdoba-Colombia, en el período comprendido entre septiembre y diciembre del 2008.

Animales. Se utilizaron cinco machos bovinos Cebú, con edades entre los 6 y 12 meses de edad, peso promedio de $200 \mathrm{~kg}$ y anillo herniario con diámetro no mayor de 8 centímetros y no menor de 6 centímetros.

Anamnésis. Todos los terneros herniados tenían como antecedentes la reducción quirúrgica con la técnica tradicional.

Hallazgos al examen clínico. Los animales seleccionados para la intervención quirúrgica presentaron a la inspección general buena condición corporal ( $3.0 \pm 0.5$, en una escala de 1-5), temperamento dócil y a nivel umbilical una neoformación sin evidencia de inflamación activa, reducible y blanda a la palpación, con la que se determinó también la presencia de anillo herniario. A la auscultación se diagnosticó ruidos intestinales en la saculación umbilical de todos los animales, lo que permitió la confirmación diagnóstica de hernia umbilical. Las ayudas paraclínicas no se consideraron necesarias por la facilidad diagnóstica de esta patología.

Autoinjerto. La obtención del material biológico injertado, fue fascia abdominal del mismo animal, como se describirá mas adelante.

Procedimiento quirúrgico. El preoperatorio de los terneros consistió en ayuno sólido de 24 horas e hídrico de 8 horas; se utilizó xilacina al $2 \%$ a la dosis de $0.1 \mathrm{mg} / \mathrm{kg}$ de peso corporal, para la tranquilización. La contención fue practicada en decúbito dorsal, donde se realizó la tricotomía de cinco veces el campo operatorio, lavado con agua y jabón, antisepsia con solución iodada $0.25 \%$. Inmediatamente se practicó la infiltración local progresiva alrededor del local quirúrgico con clorhidrato de lidocaína al 2\% a dosis de $1 \mathrm{ml} / \mathrm{cm}^{2}$ de tejido. En las cirugías se utilizó instrumental quirúrgico general.

Descripción de la técnica. La hernioplastia practicada se basó en la técnica propuesta por Alexander (9), Garnero y Perusia (5) que se describirá en tiempos quirúrgicos de la siguiente manera:

En el donador. Se realizó una incisión cráneo-caudal en piel de aproximadamente $20 \mathrm{~cm}$ de largo, paralela y a unos cinco cm del pliegue de la babilla. Seguidamente, se desbridó la piel con tijera y sus bordes se agarraron con pinzas de Allis para separarlos y permitir mejor visualización del tejido conectivo subcutáneo, el cual se desbridó y cortó con tijera recta, en la misma dirección que la incisión cutánea. La desbridación del tejido subcutáneo se completó en forma circular, lo suficiente para que permitiera identificar la fascia abdominal, como se puede apreciar en la figura 1.

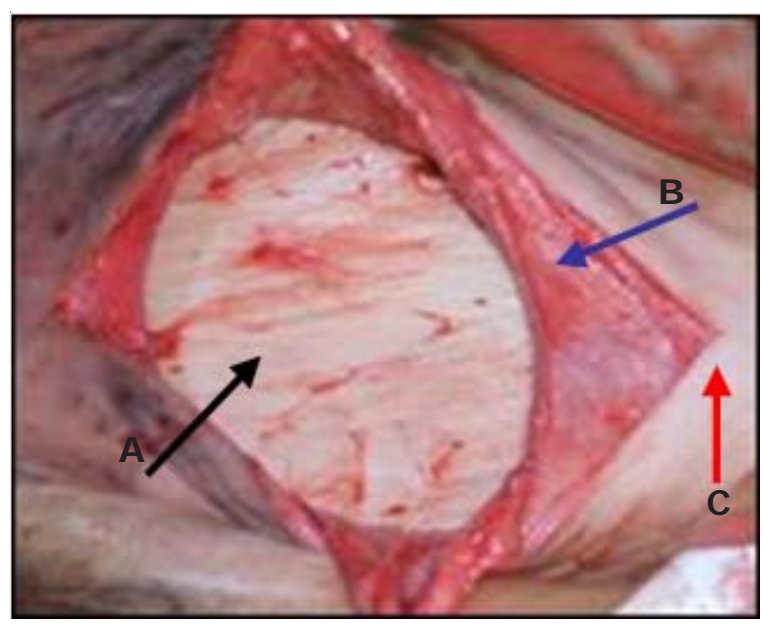

Figura 1. Fascia abdominal en el local donador (flecha A), tejido subcutáneo (flecha B) y separación de los bordes cutáneos (flecha C).

Inmediatamente, se midió con regla la cantidad de fascia abdominal a resecar, teniendo como parámetro constante para todos los casos; un diámetro de dos centímetros mayor al del anillo herniario. Se tuvo en cuenta que el colgajo de fascia obtenido estuviera libre de fibras musculares. Los tejidos incisionados, se suturaron de manera rutinaria. El colgajo a injertar se mantuvo en recipiente estéril con solución salina al $0.9 \%$ por aproximadamente 30 minutos. 
En el local receptor. Se colocaron dos pinzas de Allis en la piel, a lado y lado de la cicatriz umbilical, que sirvieron de soporte y guía para la incisión cutánea, que fue tres $\mathrm{cm}$., mayor con respecto a los bordes craneal y caudal del anillo herniario. Seguidamente, se realizó divulsión roma para liberar el colgajo de piel del saco herniario interno, con el auxilio de tijera y digitalmente, siendo necesaria la ayuda de una gasa montada sobre el dedo pulgar. Todos los animales presentaron adherencias del saco herniario interno al tejido subcutáneo. Conseguida la liberación del saco herniario interno, se procedió a su reintroducción abdominal, lo que permitió la visualización clara de los bordes del anillo herniario. No se realizó escisión del saco herniario interno en ninguno de los casos. El paso siguiente fue la colocación de dos puntos de referencia con poliamida (nylon) de 50 libras de presión en los bordes del anillo herniario a las 12:00 y 6:00 de acuerdo con las manecillas del reloj. Los puntos tuvieron como propósito la disminución del trauma tisular y la mínima manipulación del local quirúrgico.

Antes de la colocación del autoinjerto, se revivieron los bordes del anillo herniario con pequeñas incisiones con el bisturí, considerándose apropiadas cuando se conseguía ligero sangrado. I nmediatamente, se colocó el injerto de fascia abdominal en los bordes del anillo herniario para determinar que su diámetro fuera casi igual al del anillo como se puede apreciar en la figura 2. Se decidió, que el tamaño final del mismo fuera de $1.5 \mathrm{~cm}$ mayor al diámetro del anillo en todos los animales.

Seguidamente, se suturaron los bordes del autoinjerto a los bordes del anillo con puntos en " $U$ " horizontal con poliamida de 50 libras de presión con distancia de $0.5 \mathrm{~cm}$ entre punto y punto. Se tuvo en cuenta que la superficie interna del autoinjerto (superficie muscular) contactara la superficie externa del saco herniario peritoneal. Luego, se entrecruzaron dos puntos simples con poliamida de 50 libras de presión como refuerzo, como se puede apreciar en la figura 3.

El tejido conectivo se suturó con polyglactin 910 del calibre 2-0, en un patrón continuo

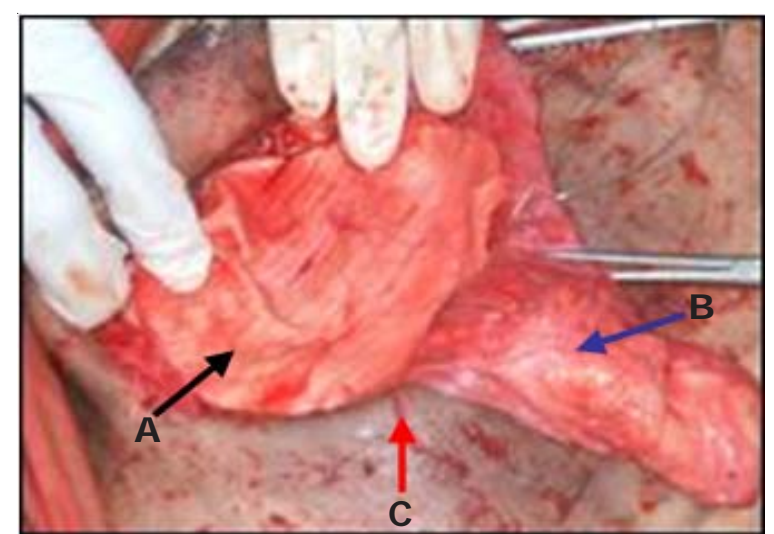

Figura 2. Colgajo de fascia abdominal (flecha A) en el local receptor, tejido conectivo subcutáneo fibroso (flecha B) y piel (flecha C).

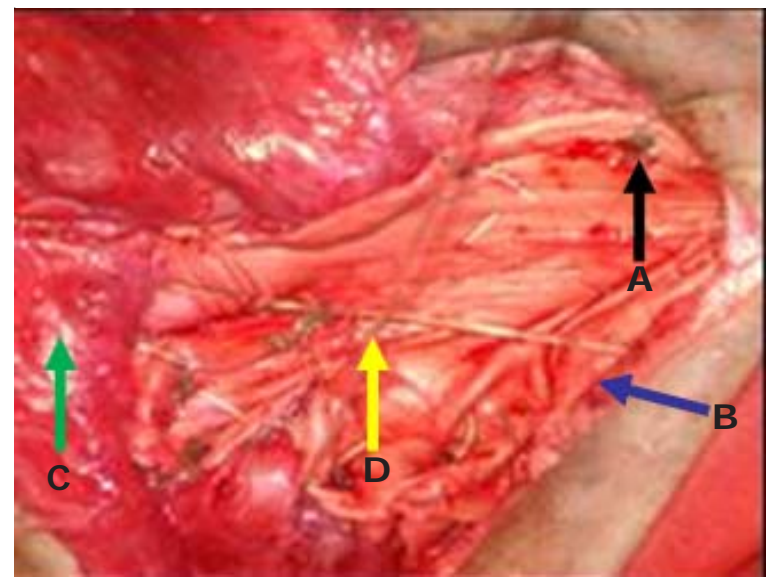

Figura 3. Suturación completa del autoinjerto de fascia abdominal (flecha B) a los bordes del anillo herniario, se observan los puntos en " $U$ " horizontal (flecha $A$ ), entrecruzamiento de los puntos simples (flecha D) y tejido conectivo fibroso (flecha C).

simple. Posteriormente, se retiró el exceso de piel y se prosiguió a la suturación de la piel con puntos en "U" horizontal, utilizando poliamida de 30 libras de presión. En ninguno de los locales quirúrgicos (donador y receptor) se colocó drenaje.

El posoperatorio de los animales se manejó en estabulación por un periodo de 45 días, en el cual recibieron siete $\mathrm{kg} /$ animal/día de pasto picado, un kg/animal/día de concentrado, sal mineralizada y agua a voluntad. Los animales se monitorearon cada 24 h por un período de 60 días. Se aplicó en todos los animales, concluida la cirugía, una dosis de betametasona un $\mathrm{mg} / \mathrm{kg} / \mathrm{im}$. El 
Tabla 1. Evaluación clínica de la cicatrización cutánea.

\begin{tabular}{cccc}
\hline Clasificación & Proceso inflamatorio & Dehiscencia de las heridas & Absceso \\
\hline 0 & Ausente & Ausente & Ausente \\
1 & Sensibilidad, edema e & Inferior a $50 \%$ & $\begin{array}{c}\text { Presente sin } \\
\text { fistulización }\end{array}$ \\
2 & $\begin{array}{c}\text { Sensibilidad, edema e } \\
\text { hiperemia moderada }\end{array}$ & Superior a $50 \%$ e inferior a & $\begin{array}{c}\text { Presente con } \\
\text { fistulización }\end{array}$ \\
3 & $\begin{array}{c}\text { Sensibilidad, edema e } \\
\text { hiperemia intensa }\end{array}$ & Igual a 100\% & - \\
\hline
\end{tabular}

tratamiento antiinflamatorio se complementó con alfaquimiotripsyn $7 \mathrm{ml} /$ animal/im/24 h/4 días con el propósito de minimizar la activación de la colagenasa y disminuir los riesgos de recidiva por debilidad tisular. Para la terapia antimicrobiana se utilizó una sola dosis de penicilina procaínica y benzatínica a razón de $15.000 \mathrm{ui} / \mathrm{kg} / \mathrm{im}$. Las heridas fueron curadas con alcohol iodado por 10 días.

Para la descripción clínica de la evolución de la cicatrización cutánea se observaron y tomaron datos a las 24 h, a los 8, 15, 30 y 60 días posteriores a la cirugía. Se evaluó la presencia del proceso inflamatorio en los focos quirúrgicos (focos donador y receptor) por 8 días, dehiscencia de las heridas quirúrgicas y absceso en el local de injertación por 15 días, y recidiva de la hernia umbilical hasta el día 60, utilizando la siguiente clasificación (Tablas 1 y 2 ):

Tabla 2. Evaluación clínica de recidiva de la hernia umbilical.

\begin{tabular}{cc}
\hline Clasificación & Recidiva \\
\hline 0 & Ausente \\
1 & Presente \\
\hline
\end{tabular}

\section{RESULTADOS}

Fue diagnosticada inflamación intensa en los locales donador y receptor en 4 animales $(80 \%)$, quedando dentro la categoría 3 y un animal presentó inflamación moderado en ambos locales, ubicándose en la categoría $2(20 \%)$. Además, se observó que la inflamación fue de mayor intensidad en el local donador.
Al evaluar las heridas, tres animales (60\%) presentaron dehiscencia en el local receptor de menos del $50 \%$, quedando dentro de la clasificación 1 . No se evidenció abscedación ni eventración en los focos donador y receptor durante el tiempo de evaluación (Tablas 1 y 2 ).

\section{SCUSIÓN}

La inflamación intensa que presentó el 80\% de los animales, posiblemente se debió al mayor tiempo de exposición a que fueron sometidos los locales quirúrgicos, lo que implica un mayor tiempo de anestesia, menor irrigación y oxigenación de los tejidos expuestos, pérdida de temperatura local, como también el mayor riesgo de contaminación (10). Cabe resaltar que la inflamación fue mayor en el donador, posiblemente por el mayor espacio muerto que dejó la porción de fascia retirada, hecho que posiblemente posibilitó el acumulo de secreciones propias del proceso inflamatorio y a la menor vascularización que tiene la fascia al ser comparado con el tejido conectivo subcutáneo, lo que influye directamente en el drenaje, semejante a lo reportado por Bojrab (11).

A pesar de la intensidad de la inflamación, solo se observó un $40 \%$ de dehiscencia de la herida cutánea en el foco receptor, atribuible posiblemente al edema intenso y la actividad colagenasa propia de las fases iníciales de este proceso. Lo anterior esta de acuerdo con los reportes de Franco et al (7), quienes observaron dehiscencia de la herida atribuida a agentes contaminantes cuando utilizaron cartílago de bovino 
homólogo y con Leber et al (12), quienes no recomiendan los tejidos del propio paciente para la reparación de hernias de la pared abdominal en humanos, por estar asociado con altos niveles de recurrencia. En contraste, Rabelo (13), no tuvo complicación cuando utilizó centro tendinoso diafragmático homólogo para la corrección de hernias umbilicales recidivantes en bovinos. La ausencia de recidiva de las hernias en los pacientes intervenidos puede sugerir la biotolerancia y resistencia del tipo de material utilizado al ser comparado con mallas sintéticas con las que se ha observado reacción de cuerpo extraño que se manifiesta clínicamente con procesos fistulosos y eventraciones $(14,15)$.
En conclusión, la recuperación quirúrgica de los cinco animales tratados indica que el procedimiento quirúrgico y el autoinjerto utilizado son adecuados para la corrección de hernias umbilicales recidivantes en terneros cebuinos con edades entre los 6 y 12 meses de edad, peso promedio de $200 \mathrm{~kg}$ y con anillo herniario entre 6 y $8 \mathrm{~cm}$ de diámetro. Además, se concluye que la técnica quirúrgica utilizada y el autoinjerto de fascia abdominal fueron eficientes en la corrección de hernia umbilical recidivante, pudiendo ser utilizada en casos semejantes.

\section{Agradecimientos.}

A Quimio Luna, MVZ.

\section{REFERENCI AS}

1. Kraus $\mathrm{KH}$, Bojrab MJ. Técnicas atuais em cirurgia de pequenos animais. São Paulo: Interamericana; 1996.

2. Figueiredo LJC. Onfalopatias de bezerros. Salvador: EDUFBA; 1999.

3. Rigs M. Umbilical hérnias, umbilical abscesses and urachal fistulas - surgical considerations. Vet Clin North Am Food Anim Pract 1995; 2: 137-147.

4. Nguhiu MJ A, Munyua SJ M, Mbithi PFM, Mbiuki SM, Mogoa EGM. How to improve the prognosis of ventral abdominal hernias in large animals: "modified" overlapping technique. Bull Anim Health Prod Afr 1991; 39: 315-320.

5. Garnero O, Perusia O. Manual de anestesias y cirugías en bovino. Argentina: Editorial Imprenta San Cayetano; 2002.

6. Ueno T, Clark PL, De la Fuente SD, Lawson C, Pappas T. Clinical Application of porcine small intestinal submucosa in the management of infected or potentially contaminated abdominal defects. J Gastrointest Surg 2004; 8: 109-112.
7. Franco da Silva LA, Da Silva OC, Eurides D, de Sousa VR, Machado MA, Guimarães L, et. al. Hernioplastia umbilical em bovino: emprego de implante de cartilagem auricular homóloga e avaliação clínica dos resultados. Acta Scientiae Veterinariae 2005; 33(1):57-62.

8. Raiser AG, Graça DL, Pippi NL, Zinn LL, Silveira DS, et. al. Homoimplante ortópico de tendão calcâneo em cães. Conservação, assepsia e implantação. Ciência Rural 2001; 31: 89-94.

9. Alexander A. Técnicas quirúrgicas en animales. Editorial Interamericana; 1981.

10. Sumano H, Ocampo L. Farmacología veterinaria. Mexico: McGraw-Hill Interamericana; 1998.

11. Bojrab MJ . Técnicas actuales en cirugía de pequeños animales. Buenos Aires, Argentina: interamericana; 2001.

12. Leber GE, Garb J L, Alexander AL, Reed WP. Long-term complications associated with prosthetic repair of incisional hernias. Arch Surg; 1998. 
13. Rabelo RE. Emprego do centro tendíneo diafragmático homólogo conservado em glicerina a $98 \%$ e em glutaraldeído a $4 \%$ como implante para hernioplastias umbilicais recidivantes em bovinos. [Tesis Mestrado]. Brasil: Universidade Federal de Goiás, Escola de Veterinária; 2003.

14. Bellon JM. Bioprótesis: Indicaciones y utilidad en la reparación de defectos herniarios de la pared abdominal. [accesado Enero 15 de 2009] URL Disponible en: http://medicyafac. wordpress.com/tag/hernia/
15. Acevedo A. Mallas sintéticas irreabsorbibles: Su desarrollo en la cirugía de las hernias abdominales. Rev Chil Cir2008; 60(5): 457-464. 